\title{
Early and Midterm Outcomes of the VSSR procedure with De Paulis valsalva graft: A Chinese single-Center Experience in 38 patients
}

\author{
Lili Xu, Feng Gao, Ping Li, Yi Xu, Shuo Liu, Bing You and Li-Zhong Sun
}

\begin{abstract}
Background: This study investigated early and midterm outcomes after valve-sparing aortic root replacement (VSSR procedure with De Paulis Valsalva graft) for acute aortic dissection or ascending aortic aneurysm in a single Chinese hospital center.

Methods: Between September 2005 to July 2013, 38 patients (84.2 \% male; mean age, $45.5 \pm 12.4$ ) underwent VSSR procedure with De Paulis valsalva graft for acute aortic dissection or ascending aortic aneurysm and were followed up clinically and echocardiographically.

Results: Among the 38 cases studied, intensive care unit stay duration was 34.5 (interquartile range, 16-34.6) days; hospital stay duration was $11.7 \pm 7.9$ days; operation time was $6.8 \pm 1.9 \mathrm{~h}$; and cross-clamping time was $154.4 \pm 42.0 \mathrm{~min}$. There was one intraoperative conversion to Bentall procedure; one re-operation for bleeding; one operative death and one case who developed complications. Mean follow-up was $39.7 \pm 21.7$ months (range, 12-108 months; cumulative rate, 1483 patients-months; follow-up rate, $94 \%$ ). At 5 and 10 years, overall freedom from valve replacement was $94 \%$ and $87 \%$; freedom from aortic regurgitation grade II or higher was $94 \%$ and $91 \%$; and freedom from reoperation was $94 \%$ and $90 \%$ years, respectively.
\end{abstract}

Conclusions: The reimplantation type of valve-sparing procedure appears to be facilitated by the use of the De Paulis valsalva graft with satisfactory perioperative and midterm results.

Keywords: Valve-sparing aortic root replacement, De Paulis graft VSSR procedure

\section{Background}

Until the introduction of valve-sparing aortic root replacement (VSSR) in 1992 [1], acute aortic dissection or ascending aortic aneurysm was traditionally treated by replacing the root with a composite valve graft [2], which was limited by patient's postoperative quality of life and lifelong dependency on anticoagulation. VSSR has been reported to be associated with favorable longterm outcomes and mortality [3]. We report here on the short- and midterm outcomes of 38 patients who underwent VSSR with De Paulis Valsalva graft for acute aortic

\footnotetext{
* Correspondence: lizhongsun@outlook.com

Department of Cardiovascular Surgery, Beijing Institute of Heart, Lung and Blood Vessel Diseases, Beijing Anzhen Hospital, Capital Medical University, 2 Anzhen Road, Beijing 100029, China
}

(c) 2015 Xu et al. Open Access This article is distributed under the terms of the Creative Commons Attribution 4.0 International License (http://creativecommons.org/licenses/by/4.0/), which permits unrestricted use, distribution, and reproduction in any medium, provided you give appropriate credit to the original author(s) and the source, provide a link to the Creative Commons license, and indicate if changes were made. The Creative Commons Public Domain Dedication waiver (http://creativecommons.org/publicdomain/zero/1.0/) applies to the data made available in this article, unless otherwise stated.

\section{Methods}

From September 2005 to July 2013, 38 patients (32 males, $84.2 \%$; mean age, $45.5 \pm 12.4$; range, $24-69$ years) underwent VSSR procedure at Anzhen Hospital, Beijing. As summarized in Table 1, mean age of the overall cohort $(n=38)$ was $45.5 \pm 12.4$ years (range, 24-69); $84.2 \%$ were male; mean body mass index (BMI) was $21.78 \pm 8.4 ; 18(47.4 \%)$ patients were greater than NYHA class 3; EuroScore II was 13.9 (IQR, 1.83-23.3); 22 $(57.9 \%)$ patients had greater than moderate aortic valve regurgitation; 7 (18.4\%) patients had Marfan syndrome and LDS; and 16 (42.1\%) had aortic dissection. Following 
Table 1 Preoperative characteristics $(n=38)$

\begin{tabular}{|c|c|}
\hline Variables & Values \\
\hline Age, years (range) & $45.5 \pm 12.4(24-69)$ \\
\hline Male gender & $32(84.2 \%)$ \\
\hline Female gender & $6(15.8 \%)$ \\
\hline Weight, Kg & $73.9 \pm 12.3$ \\
\hline Height, cm & $173.7 \pm 9.3$ \\
\hline BMl & $21.78 \pm 8.4$ \\
\hline$B S A, m^{2}$ & $1.97 \pm 0.2$ \\
\hline \multicolumn{2}{|l|}{ NYHA classification } \\
\hline Class 1 & 0 \\
\hline Class ॥ & 20 \\
\hline Class III & 15 \\
\hline Class IV & 3 \\
\hline Hypertension & 15 \\
\hline Chronic obstructive pulmonary disease & 3 \\
\hline Smoking & 13 \\
\hline Peripheral vascular disease & 3 \\
\hline Preoperative carnine & $86.5 \pm 24.0$ \\
\hline Preoperative atrial fibrillation or flutter & 1 \\
\hline EuroScore II & $13.9(\mathrm{IQR}, 1.83-23.3)$ \\
\hline \multicolumn{2}{|l|}{ Preoperative UCG } \\
\hline LVEF & $64.0 \pm 6.5$ \\
\hline Maximum aortic arch diameter, mm & $31 \pm 5.9$ \\
\hline Maximum aortic root diameter, $\mathrm{mm}$ & $47.5 \pm 11.0$ \\
\hline Maximum diameter, mm & $48.9 \pm 11.1$ \\
\hline Sinotubular junction diameter, mm & $45.0 \pm 9.9$ \\
\hline Maximum aortic annulus diameter, $\mathrm{mm}$ & $25.8 \pm 2.7$ \\
\hline \multicolumn{2}{|l|}{ Aortic valve regurgitation } \\
\hline None & 8 \\
\hline Mild & 4 \\
\hline Moderate & 6 \\
\hline Moderately severe & 3 \\
\hline Severe & 13 \\
\hline Mitral regurgitation & 13 \\
\hline Tricuspid regurgitation & 7 \\
\hline Marfan syndrome and LDS & 7 \\
\hline Non-connective tissue disease & 31 \\
\hline Aneurysm without dissection & 22 \\
\hline Acute dissection & 16 \\
\hline DeBakey I & 14 \\
\hline DeBakey ॥ & 2 \\
\hline Bicuspid aortic valve & 2 \\
\hline
\end{tabular}

Table 2 Perioperative data $(n=38)$

\begin{tabular}{ll}
\hline Variable & \\
\hline Operation time, hours & $6.8 \pm 1.9$ \\
Cross-clamping time, minutes & $154.4 \pm 42.0$ \\
Bypass time, minutes & $203.1 \pm 60.1$ \\
Ventilation time, hours & $35.2 \pm 29.8$ \\
Intensive care unit stay duration, hours & 34.5 (IQR, 16-34.6) \\
Postoperative hospital stay duration, days & $11.7 \pm 7.9$ \\
Additional procedures & \\
Coronary artery bypass grafting & 4 \\
Mitral valve replacement & 1 \\
ASD or VSD closure & 4 \\
Arch and "Trunk" procedure & 16 \\
Postoperative Complications & \\
Postoperative arrhythmias & 11 \\
Thoracotomy hemostasis & 1 \\
Surgical infections & 3 \\
Psychiatric symptoms & 5 \\
Acute renal failure & 3 \\
Postoperative drainage, mL & $1201.3 \pm 757.7$ \\
Death & 1 \\
\hline
\end{tabular}

guidelines [4], asymptomatic patients with an aortic root diameter of more than $55 \mathrm{~mm}$ due to an aneurysm of degenerative origin were selected for operation. If the patient had been diagnosed with Marfan or LDS, VSSR procedure was indicated when the aortic root diameter exceeded $45 \mathrm{~mm}$. VSSR was performed in patients with acute aortic dissection if the aortic root was destroyed regardless of the root diameter. This study was approved by the Regional Ethics Committee of our hospital and all patients signed informed consents.

\section{Surgical technique [5]}

All procedures were performed through a median sternotomy using cardiopulmonary bypass. Patients undergoing isolated aortic root replacement received right atrial twostage and central aortic cannulation. In most cases, antegrade cerebral perfusion was used throughout the period of hypothermic systemic circulatory arrest. After ascending aorta was clamped, the aorta was then transected, the aortic cusps were carefully inspected for prolapse, tears, calcification and perforations. After careful assessment of pertinent parameters to determine VSSR procedure methodology, the root was circumferentially dissected down to the aortic annulus nadir and each coronary artery was sutured as a button, freed and mobilized. A De Paulis valsalva graft (Gelweave Valsalva graft, Vascutek Ltd, Renfrewshire, Scotland) was secured to the aortic annulus and passed on a horizontal plane below the aortic cusps. Three aortic 
junction crests were anchored with 4-0 prolene suture inside the valsalva graft and throughout the graft wall up to the height mark. The aortic annulus then were sutured inside the valsalva graft using interrupted $2-0$ polypropylene horizontal mattress sutures, passed though the wall of the graft and tied on the outside. The graft was re-implanted on the left ventricular outflow, and the coronary buttons then were re-implanted on the graft using 6-0 polypropylene. The distal anastomosis of the graft was continuously sutured to the aorta with 4-0 prolene (in aortic arch replacement, it was sutured to the other graft) (Table 2).

\section{Follow-up}

Early death was defined as that occurring within 30 days of the operation. Calculation of postoperative hospital stay duration did not include early death cases. The median duration of follow-up for survivors was $39.7 \pm 12.7$ months (range, 12-108 months). To obtain follow-up information, clinical staff would first contact patients via phone. If patient could not be reached by telephone, letters were sent to the patient's address. No patient was lost to follow-up in the early stage. Follow-up echocardiography was performed and evaluated for all patients. Postoperative death and repair failure requiring reoperation (severe aortic regurgitation, endocarditis and graft infection) after VSSR were defined as adverse events. Intraoperative conversion to a valve-replacing procedure due to severe valve regurgitation also was considered an adverse event (Figs. 1 and 2).

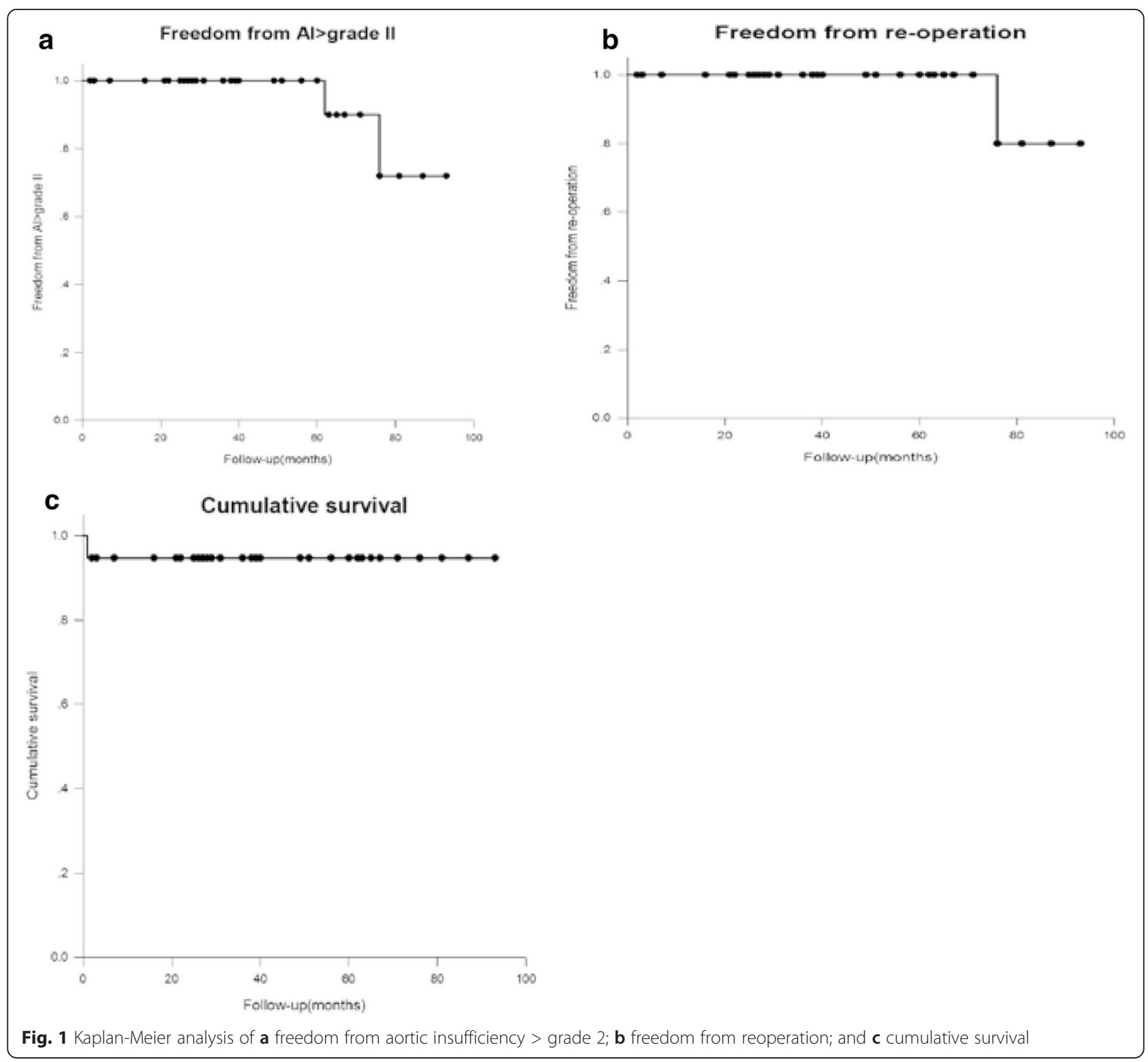




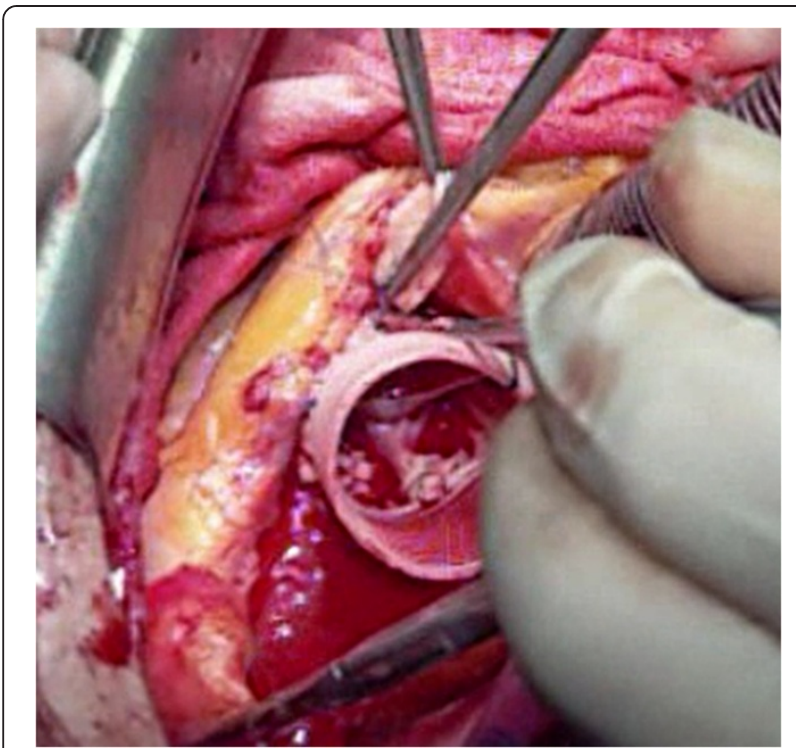

Fig. 2 VSSR procedure with De Paulis Valsalva graft

\section{Statistical methods}

Data are presented as number and percentage for all discrete variables. Continuous variables are presented as mean \pm standard deviation or median and interquartile range. Group comparisons were performed using the student $\mathrm{t}$ test for normally distributed variables, the MannWhitney $U$ test for ordinal variables, and the Fisher exact test for categorical variables. A $p$ value less than 0.05 was considered statistically significant. Overall survival and freedom from adverse events statistics were estimated with the Kaplan-Meier survival model. Data were analyzed with a commercially available software (SPSS Statistics 21; SPSS, IBM, New York, NY).

\section{Results}

\section{Perioperative outcome}

The VSSR procedure was performed in 37 patients, and one patient underwent intraoperative conversion to Bentall procedure. Within 30 days, there was one (2.6\%) death secondary to lung infection coupled with multiple organ failure; 16 (42.1\%) emergency operations; and one (2.6\%) patient required re-exploration for bleeding. Additional procedures included CABG in 4 (10.5 \%) patients; and arch and "trunk" procedure in 16 (42.1\%) patients. Five $(13.2 \%)$ patients developed psychiatric symptoms, and $3(7.9 \%)$ acute renal failure.

Mean duration of intensive care unit stay was 34.5 (IQR, 16-34.6) hours; and mean hospital stay was $11.7 \pm$ 7.9 days. At discharge, mean operation time was $6.8 \pm 1.9$ $\mathrm{h}$, and mean cross-clamping time was $154.4 \pm 42.0 \mathrm{~min}$. Aortic regurgitation less than grade I was documented echocardiographically in all 37 patients (one conversion to Bentall procedure) after the VSSR procedure, a significant reduction from the baseline of $20(p<0.001$, Table 3$)$.

\section{Midterm follow-up}

During mean follow-up time of $39.7+12.7$ months (range, 12-108 months; cumulative rate, 1483 patient-months; and follow-up rate, $94 \%)$, there was one death $(2.7 \%)$ secondary to lung infection within one year; one patient $(2.7 \%)$ experienced worsening of aortic regurgitation requiring reoperation and underwent aortic valve replacement; and the degree of regurgitation remained constant in most patients.

At 1 and 5 years, overall freedom from valve replacement was $94 \%$ and $87 \%$; freedom from aortic regurgitation grade II or higher was $94 \%$ and $91 \%$ (included the one patient re-operated for aortic insufficiency); and freedom from reoperation was $94 \%$ and $90 \%$ years, respectively. Freedom from reoperation in patients without additional cusp repair was $92 \%$ and $87 \%$ at 1 and 5 years, respectively, which was not significantly different from those patients who required additional cusp repair (freedom from reoperation of $100 \%$ at 5 years, $P=0.211$ ).

\section{Discussion}

As an alternative method to Bentall operation for acute aortic dissection or ascending aortic aneurysm, David described an approach in which the aortic root wall is replaced by a straight tubular prosthesis thereby overcoming the shortcomings of lifelong anticoagulation. Currently, there are at least 5 modified procedures named

Table 3 Follow-up data

\begin{tabular}{|c|c|c|c|c|c|c|c|}
\hline Variables & $\begin{array}{l}\text { Pre-op } \\
(n=38)\end{array}$ & $\begin{array}{l}\text { Hospital discharge } \\
(n=37)\end{array}$ & $\begin{array}{l}1 \text { year follow-up } \\
(n=27)\end{array}$ & $\begin{array}{l}5 \text { years follow-up } \\
(n=12)\end{array}$ & $P$ value 1 & $P$ value 2 & $P$ value 3 \\
\hline Aortic annulus diameter & $25.8 \pm 2.7$ & $27.6 \pm 1.9$ & $27.8 \pm 2.4$ & $28.0 \pm 1.9$ & $<0.001$ & 0.884 & 0.769 \\
\hline Aortic sinus diameter & $48.9 \pm 11.1$ & $31.8 \pm 3.1$ & $30.8 \pm 2.7$ & $33.5 \pm 3.3$ & $<0.001$ & 0.544 & 0.875 \\
\hline Aortic regurgitation (moderate to severe) & 20 & 0 & 1 & 2 & $<0.001$ & 0.226 & $<0.001$ \\
\hline LVEF & $64.0 \pm 6.5$ & $63.4 \pm 6.5$ & $63.2 \pm 6.1$ & $61.5 \pm 6.6$ & 0.634 & 0.769 & 0.560 \\
\hline LV end-systolic diameter & $34.4 \pm 5.6$ & $31.9 \pm 4.8$ & $32.4 \pm 2.9$ & $31.5 \pm 3.6$ & $<0.001$ & 0.812 & 0.661 \\
\hline LV end-diastolic diameter & $53.7 \pm 6.1$ & $48.4 \pm 5.5$ & $48.7 \pm 4.0$ & $49.4 \pm 4.9$ & $<0.001$ & 0.793 & 0.724 \\
\hline
\end{tabular}


David I to V [6] and although evidence on which one is better is lacking, a growing number of surgeons have been using David procedures for patients with connective tissue diseases. However, in the study of Marfan syndrome patients by Cameron and colleagues [7], the intrinsic leaflet structure in the graft without sinus structure deteriorated rapidly, undergoing prolapse and elongation possibly secondary to loss of tonicity and the free margin impacting the straight wall of the graft; long-time abrasion would therefore affect aortic valve leaflets. To address this limitagraft which recreates sinuses and yields relatively favorable early outcomes: patients who underwent reimplantation with the Valsalva graft had a significantly smaller annular diameter, less bleeding, and less residual aortic insufficiency; however, the authors stressed that a larger patient cohort and longer follow-up was warranted.

Since 2005, our hospital has been using the VSSR procedure with De Paulis valsalva graft in patients with ascending aorta acute dissection or root aneurysm. As reported in this overview of our experience, one patient required reoperation for bleeding and there was only one death, yielding an operative mortality of $2.6 \%$, and no significant perioperative morbidity. One patient was converted to a Bentall procedure intraoperatively. Early outcomes of the 38 patients demonstrated no dilatation, and no significant aortic insufficiency or progression thereof.

Several experiences and observations are worth highlighting. First, in our experience, success rate improved after a learning curve for surgeons' comprehensive understanding of anatomy and function of the aortic root and valve complex. Second, among the 38 patients, 16 who underwent VSSR procedure for acute aortic dissection, all survived without important events. Relative to the overall population studied, these patients were younger (41.8 \pm 10.2 years), with a higher EuroScore II (23.4 \pm 7.2 ), and smaller maximum aortic root diameter $(44.7 \pm 7.6$ $\mathrm{mm})$. The VSSR procedure appears to have been a good choice for these patients, however, further follow-up data are warranted.

Third, although VSSR procedure was reserved for cases with absence of severe aortic regurgitation, and presence of trileaflet aortic valve and normal cusps, it was performed in 2 cases or bicuspid aortic valve and 7 Marfan syndrome cases to honor patient's desire for freedom from lifelong anticoagulation dependency. Although perioperative outcomes of VSSR were favorable, which could be related to the young age of the patients $(40.7 \pm 9.9$; range, 24-55), long-term durability of VSSR is unknown in these cases because mean follow-up was 39.6 months (IQR, $3-71$ ). If the conclusions of this study can be extended to these patient subsets, the valve and cusp repair strategies could further change the surgical approach in bicuspid aortic valve and Marfan syndrome cases [9-11].

This study has several limitations, including its small sample size, and limitations in statistical power to comparatively analyze subset of patients [12, 13]. Despite these limitations, this study with up to 9 years of followup documented excellent early and midterm outcomes in selected patients who underwent aortic root replacement for aneurysms.

\section{Conclusion}

This procedure appears to be a safe and appropriate alternative method to mechanical composite valve graft root replacement in patients who wish to avoid anticoagulation dependency with warfarin.

\section{Abbreviations}

IQR: interquartile range; VSSR: valve-sparing aortic root replacement; NYHA: New York Heart Association.

\section{Competing interests}

The authors declare that they have no competing interests. No funding was received for this study.

\section{Authors' contributions}

LX designed the study, performed the statistical analysis, and drafted the manuscript. All authors performed the VSSR procedures and read and approved the final manuscript.

\section{Acknowledgements}

We thank Mrs. Lu Zheng for her skillful contribution as operating room nurse.

Received: 25 November 2014 Accepted: 28 October 2015

Published online: 19 November 2015

\section{References}

1. David TE, Feindel CM. An aortic valve-sparing operation for patients with aortic incompetence and aneurysm of the ascending aorta. J Thorac Cardiovasc Surg. 1992;103:617-21.

2. Bentall $H$, De Bono A. A technique for complete replacement of the ascending aorta. Thorax. 1968;23:338-9.

3. Shrestha M, Baraki H, Maeding I, Fitzner S, Sarikouch S, Khaladj N, et al. Long-term results after aortic valve-sparing operation (David I). Eur J Cardiothorac Surg. 2012;41:56-62.

4. Bonow RO, Carabello BA, Chatterjee K, de Leon AC Jr, Faxon DP, Freed MD, et al. 2008 focused update incorporated into the ACC/AHA 2006 guidelines for the management of patients with valvular heart disease. J Am Coll Cardiol. 2008;52(13):e1-142.

5. Demers P, Miller DC. Simple modification of "T. David-V" valve-sparing aortic root replacement to create graft pseudosinuses. Ann Thorac Surg. 2004;78:1479-81

6. Shimizu H, Yozu R. Valve-sparing aortic root replacement. Ann Thorac Cardiovasc Surg. 2011;17(4):330-6.

7. Cameron DE, Alejo DE, Patel ND, Nwakanma LU, Weiss ES, Vricella LA, et al. Aortic root replacement in 372 Marfan patients: evolution of operative repair over 30 years. Ann Thorac Surg. 2009;87:1344-50.

8. De Paulis R, De Matteis GM, Nardi P, Scaffa R, Colella DF, Chiarello L. A new aortic Dacron conduit for surgical treatment of aortic root pathology. Ital Heart J. 2000;1:457-63.

9. Kvitting JP, Kari FA, Fischbein MP, Liang DH, Beraud AS, Stephens EH, et al. David valve-sparing aortic root replacement: equivalent mid-term outcome for different valve types with or without connective tissue disorder. J Thorac Cardiovasc Surg. 2012;145:117-26. 127.e111-15; discussion 126-7.

10. David TE, Armstrong S, Manlhiot C, McCrindle BW, Feindel CM. Long-term results of aortic root repair using the reimplantation technique. J Thorac Cardiovasc Surg. 2013;145:S22-5. 
11. de Kerchove L, Boodhwani M, Glineur D, Poncelet A, Verhelst R, Astarci P, et al. Effects of preoperative aortic insufficiency on outcome after aortic valve-sparing surgery. Circulation. 2009;120:S120-6.

12. Aicher D, Kunihara T, Abou Issa O, Brittner B, Graber S, Schafers HJ. Valve configuration determines long-term results after repair of the bicuspid aortic valve. Circulation. 2011:123:178-85.

13. Volguina IV, Miller DC, LeMaire SA, Palmero LC, Wang XL, Connolly HM, et al. Valve-sparing and valve-replacing techniques for aortic root

replacement in patients with Marfan syndrome: analysis of early outcome. J Thorac Cardiovasc Surg. 2009;137:1124-32.

\section{Submit your next manuscript to BioMed Central} and take full advantage of:

- Convenient online submission

- Thorough peer review

- No space constraints or color figure charges

- Immediate publication on acceptance

- Inclusion in PubMed, CAS, Scopus and Google Scholar

- Research which is freely available for redistribution 